over intrusive therapies, mechanical ventilation or resuscitation; and finally, discusses the ethical dimensions of the duty to inform others. William J Winslade argues firmly that riskcarriers, and if not them, their doctors, have compelling responsibility to inform others who have been put at risk.

The final section discusses from various perspectives the many issues which AIDS has raised for public health policy. Mandatory screening, contact tracing and quarantine make their appearance, along with the questions of discrimination in employment, in the armed forces, and over insurance. The most telling contribution in this section is from the San Francisco epidemiologist Andrew Moss, who details some of the ethical and moral choices which arose in practice over the closure of the gay bathhouses in that city. Moss, who supported the closure, argues that an aggressive voluntary public health policy must be developed in order to prevent the rise of 'new right' coercive solutions.

Moss's contribution is interesting as an historical account by a key participant in the San Francisco AIDS story. The problem with the rest of the book is two-fold. Much of the material it presents is, in AIDS terms, quite dated. It is also entirely Americanfocused. The issues raised are universal but the empirical material presented is specific to one country. And in the US, as in other countries, much has happened since 1986 which has implications for the ethical, as well as other, dimensions of the disease.

VIRGINIA BERRIDGE Senior Lecturer AIDS Social History Programme London School of Hygiene and Tropical Medicine

\section{The Unheeded Cry: Animal Consciousness, Animal Pain and Science}

Bernard E Rollin, xviii + 308 pages, Oxford, £17.50, Oxford University Press, 1989

The main premise of this book is that, while commonsense should have us recognise that animals can think, feel and suffer, scientists have long denied that we can know what animals are experiencing. This has led to a cavalier attitude towards animal use, animal pain and the moral questions that they raise. As a result, it is not only the animals used in scientific research which have suffered, but also science itself, because failure to pay sufficient attention to animal feelings can distort the results of the experiments in which they are used. Happily, increased societal concern about animals, not least in the scientific community itself, at least in some parts of the world, is forcing science to turn back towards the commonsense view.

Professor Rollin's book contains an introductory chapter, plus chapters on animal consciousness as an object of study; aspects of change in science and philosophy; the tortuous path from Romanes to Watson; animal pain - the 'ideology cashed out'; morality and animal pain; consciousness lost; and consciousness regained, in psychology, in ethology and beyond; together with notes on each chapter, a bibliography and an index. These chapters contain a wealth of historical detail and analysis, and illustrate how attitudes among scientists have been engendered and are changing.

Being both a professor of philosophy and a professor of physiology and biophysics, Bernard Rollin is uniquely qualified to discuss the development of attitudes among scientists and to influence them. However, this book was clearly written with his philosopher's hat on, as it is very long. While it will undoubtedly be of value to philosophers and science historians, most active laboratory research scientists would not have the time or inclination to read such a book. They look to short reviews or letters to Nature or Science to inform them of new developments in their fields, and are faced with editorial pressures to keep their own published papers short. This lack of opportunities for effective communication and dialogue is a major cause of the underlying problem of poor communication in this field. Perhaps the only solution is the introduction into all higher education in the sciences of ethics courses of the kind pioneered by Professor Rollin at Colorado State University.

DR MICHAEL BALLS Chairman of the Trustees of Fund for the Replacement of Animals in Medical Experiments (FRAME) and

Professor-elect of Medical Cell Biology, University of Nottingham Medical School

\section{Philosophy and Medical Welfare}

Edited by J M Bell and Susan Mendus, 126 pages, Cambridge, $£ 8.95$, Cambridge University Press, 1988

This slim volume is very well worth reading. It stems from a Royal Institute of Philosophy Conference held at York in September 1987. Inevitably, as with all conference books, there is some unevenness among the contributions, and some lack of unity. Nevertheless in this instance quality, readability and relevance never fall below an acceptable level.

Not surprisingly, Quality Adjusted Life Years (QALYs) attract a good deal of attention in the book. Four of the seven essays in one way or another address them. Since the authors include Alan Williams (one of the principal architects of the notion) and John Harris (its sharpest critic), the reader is assured of a diversity of views, all of them worth serious attention. Fortunately, Alan Williams does not simply go over the familiar ground of explaining QALYs and arguing the case for them, but describes a survey aimed at eliciting views about the importance of help at one stage of life compared with others. Thus he is not concerned in this essay with preferences about relative states of health - various degrees of pain and handicap compared with feeling well - but with public views about the relative importance of helping infants (for example) compared with people who are looking after elderly relatives, or parents bringing up children. This is a well written account of an inquiry, with a touch of the detective story. He does not seek to justify it, nor explain how he intends to use the results, but it is not hard to guess.

Nor is it difficult to predict that John Harris will view any such enterprise with horror. What he does in this volume, with eloquence and no concessions whatever to the economists, is to argue for the superiority of the equality principle over any notion of cost benefit. He cheats a little by exaggeration. For example, 'if you and I are different ages but both want to live, then it is unfair to prefer your life to mine simply because you are three months younger'. A threemonth difference is one thing, but what if the difference in life expectancy is ten years or twenty or thirty? He would do better to concentrate on these more substantial and difficult choices than to 
pretend that small differences are likely to be used by anyone as determinants of life or death. He nevertheless makes some excellent points (for example, should a marginal difference for a very large number of people outweigh substantial gains for a few?) and is perfectly entitled to maintain that a lottery is ultimately the only fair method for determining who has access if not all can be treated.

Lockwood also deals with QALYs, and the running battle between Williams and Harris. He suggests that a principle of justice that is fundamental to the Hippocratic tradition - namely 'to each according to his need' - should act as a constraint on Williams's welfare maximisation principle. Broome is similarly concerned with the balance between maximising and fairness, contending that both have to be weighed and that they normally pull in different directions. Neither is overriding, and it will almost certainly be right to trade off some of one against the other. He sees QALYs as a valuable, but in the end fatally flawed, attempt to assess good in medical contexts.

It seems to me a pity during this high quality academic debate about the theory of QALYs that relatively little attention is being given to improving the data on which they are based, and virtually none to their appropriate use. For example it makes all the difference in the world whether they are used to assess competing therapies for the same patient or to decide between patients, whether they are used primarily to jolt us into asking whether the historical allocation of resources seems seriously out of line with rationality and justice, or whether (as most commentators appear to assume) QALYs are to be fed into a black box somewhere from which will come a resource allocation printout to be applied slavishly to clinical choices. QALYs can be improved. With improvement they will be a helpful aid to questioning. They must never be used as a sole criterion nor as a mechanical substitute for informed and compassionate human judgement.

The essays that do not deal with the volume's dominant theme are the ones by Weale, Goodin and Hollis. Weale raises the neglected question of what is due to providers and how, in a system subject to the monopoly bargaining power of the state, we can achieve justice in the incomes paid to those who work in the National Health Service. Goodin argues (in relation to heroic therapies) that there should always be a presupposition against heroic intervention if only because it raises false hopes. Hollis, with a delightfully written case-study, discusses two dilemmas of the physician. The first is the responsibility to weigh what the physician thinks is in the patient's best interests versus what the patient appears to want - one would have to have very compelling reasons to override the latter. The second is the two-fold loyalty to the patient and (when resources are stretched to their limit) to the community. This second dilemma is highly relevant to the current emotionally charged debates about doctors as budget-holders. There are no simple solutions to this, but also no escape.

The volume includes one perfectly delightful typo. We are told that instead of QALYs 'a weighted lorry would be fairer'. For lorry, read lottery. Nevertheless it is a memorable image.

ROBERT J MAXWELL Secretary/Chief Executive, The King's Fund, 14 Palace Court, London W2 4HT.

\section{Follies and Fallacies in Medicine}

\section{P Skrabanek and J McCormick, 170 pages, Glasgow, £7.95, Tarragon Press, 1989}

The Dublin-based authors of this witty, lucid and intentionally provocative treatise have recently acquired a certain amount of notoriety as contemporary scourges of inflated medical egos. They are not alone in attacking past and present claims made for or on behalf of clinical medicine to have been the major instrument of greater longevity, nor in showing how fallacious and flimsy have been and still are some of the claims of medical notables to knowledge of disease processes and the efficacy of therapeutic measures. They number themselves proudly among the 'abominable "no-men".

However, in this book, and elsewhere, they have other targets. They have turned on their allies in some of the iconoclastic arguments - that is on protagonists of public health and preventive medicine on the one hand and proponents of alternative medicines on the other - and accused them of allowing their morally-inspired zeal for social betterment as they see it to outweigh sober scientific judgement. In so doing, they imply that many contemporary health zealots are imposing their own moral standards on many innocent people who may be duped into foregoing harmless hedonistic practices which are unlikely to shorten their life-spans significantly or reduce the overall quality of their existence.

The book has six chapters. The first deals with placebos. The authors claim that a large element of modern therapeutics is no better than a placebo, but that this is virtually concealed from medical students and is inadequately researched. As a result they imply that a measure of self-deceit is rife among medical practitioners as well as deceit of patients; but they do not make clear whether in eliminating the first - selfdeceit - which they advocate, presumably by inducing greater scepticism and understanding of the nature of therapy, practitioners' will no longer be on the horns of their moral dilemmas.

The second chapter lists and describes 26, somewhat broadly defined, fallacies commonly observed in medical reasoning. In at least one listed case, that of randomised controlled trials, the authors suggesf that not all the reputedly ethical arguments that have been used agains conducting them have been genuin $e^{+}$ and justifiable. Rather they are advanced, it is claimed, by those who wish to defend existing practices.

The third chapter is concerned with the temptation to diagnose and treat when doctors are faced by conditions whose causes cannot be ascertained. Diagnosis of, as the authors call it, nondisease, enhances the power which can be exercised over patients. The consequent labelling can itself damage, potentially irrevocably. 'All therapeutic activity directed at non-diseases is harmful; sometimes the harm is substantial' is their main conclusion.

The fourth chapter examines some recent developments in preventive medicine, which they claim have been largely exempt from ethical consideration. Their targets in the chapter are those who would change the diets of whole populations as well as the proponents of wholesale screening for breast and cervical cancer and the treatment of slightly elevated blood pressures. They see in it the potentially malign influence of the all-powerful state which seeks better to control its subjects and utilises the medical profession so to do. They conclude categorically that, while it is legitimate for doctors to maintain 'a certain modicum of therapeutic optimism when caring for the sick' (for example the cancer sufferer), the extension of 